\title{
Parasites in fisheries and mariculture
}

\author{
J. T. TIMI ${ }^{1} *$ and $\mathrm{K} . \mathrm{MACKENZIE}^{2}$ \\ ${ }^{1}$ Laboratorio de Parasitología, Facultad de Ciencias Exactas y Naturales, Instituto de Investigaciones Marinas y Costeras \\ $(\operatorname{IIMy}$ C), Universidad Nacional de Mar del Plata-CONICET, Funes 3350, (7600) Mar del Plata, Argentina \\ ${ }^{2}$ School of Biological Sciences (Zoology), University of Aberdeen, Tillydrone Avenue, Aberdeen AB24 2TZ, Aberdeen, UK
}

(Received 3 Fune 2014; revised 6 Fuly 2014; accepted 6 Fuly 2014)

Traditionally, parasitology has been concerned with the harmful effects of parasitic organisms; it is basically an applied science. Since its founding in the field of medicine, and later in veterinary medicine, parasitology has been mainly devoted to generating knowledge, which is applicable to parasite control and management, and eventually to their eradication. However, the complexity of parasitism, as revealed over recent decades by workers in various specialisms of parasitology, makes the application of management and control measures very difficult in natural environments. This is particularly true in the marine realm, where however some applied aspects of parasitology, other than those devoted to control and management of parasites, have been shown to be of great importance for fisheries, human health, biological control of introduced species and environmental sciences (Rohde, 2002). The relationship of parasitology with mariculture practices, which are carried out mostly on artificial and controlled systems, follows a more classical approach, focusing on the development of strategies of prevention, management and control of pathogens.

The aim of this Special Issue is to provide an updated review of those aspects of parasitology that are currently applied to two of the main productive human activities in the world ocean, namely fisheries and mariculture. Both topics are examined under two different perspectives in relation to their own specific problems.

\section{MARINE PARASITES IN FISHERIES}

Fisheries constitute a significant proportion of ocean production, and overexploitation has affected their productivity and the ecosystems supporting them. Over time, with the advancement of technology, fishing has progressively spread over the world oceans. However, after a long period of steady increase, world capture fishery production has almost stopped growing since the mid-1980s (FAO, 2012). The decrease in global catch can be explained by the

* Corresponding author. Laboratorio de Parasitología, Facultad de Ciencias Exactas y Naturales, Instituto de Investigaciones Marinas y Costeras (IIMyC), Universidad Nacional de Mar del Plata-CONICET, Funes 3350, (7600) Mar del Plata, Argentina. E-mail: jtimi@mdp.edu.ar sequential depletion of individual stocks. Indeed, according to the report on the state of world fisheries and aquaculture published by FAO (2012), the proportion of non-fully exploited stocks has decreased gradually. In contrast, the percentage of fully exploited and overexploited stocks continues to increase. Plans to rebuild stocks and to manage them effectively to avoid further decline are, consequently, necessary to restore or maintain the full and sustainable productivity of fisheries. This requires an assessment of the biological status of fisheries, which in turn relies on detailed stock assessments. This information, however, is not available for the overwhelming majority of exploited stocks and fisheries globally (Kleisner et al. 2012), with fisheries lacking formal assessment comprising $>80 \%$ of the global catch (Costello et al. 2012).

One way to mitigate uncertainty on sustainability of global fisheries is to achieve precise assessments of resource abundance in space and time and, as a first step, collecting information on stock structure. Different approaches have been used in identifying stocks, including catch data, life-history characteristics, mark-recapture, otolith microchemistry, morphometrics, genetics and parasites, with holistic approaches, involving a broad spectrum of complementary techniques, being recommended for future stock identification studies (Begg and Waldman, 1999).

Since the first study describing the use of a naturally occurring parasite to investigate the stock structure of a marine fish (Herrington et al. 1939) other studies followed at an increasing rate (MacKenzie, 1987). In these early days the method was viewed as something of a curiosity and it took many years before most fishery managers were persuaded to accept the method as worthy of their serious consideration. This is in contrast to the past 20 or so years, during which time parasite tags have come to be regarded as valuable tools for use in stock identification and in determining the degree of connectivity between populations of marine fish (Cadrin et al. 2005). This change in attitude is partly due to the increase in our knowledge of the life cycles and ecology of marine fish parasites, which has greatly increased the efficiency of the method and facilitated its use. It can also be partly attributed to 
the success of recent studies in which the results from the use of parasite tags have either supported those of other methods of stock identification or in which they have been used as an integral part of a multi- or interdisciplinary study.

At present, the use of parasites as biological tags is a well-established methodology, with a general consensus on a series of methodological guidelines, but with a variable degree of application throughout the world. In this Special Issue, the history, current status and perspectives of the use of parasites as biological tags are reviewed by specialists from different sectors of the world ocean. Cantatore and Timi (2014) review the use of parasites as biological tags for fish stock delineation off the Atlantic coast of South America, analysing the advantages and constraints of this methodology in the region and providing recommendations for future research. The authors also expand the concept of biological tags from local to regional scales, which can provide essential information to delineate ecosystem boundaries for host communities. On the opposite side of South America, George-Nascimento and Oliva (2014) summarize results of research using parasites in fish population studies in the Southeastern Pacific, analysing the importance of host species body mass to the variability of parasite infracommunities and recommending regular and long-term investigations and the consideration of the effects of fishing and natural oscillations on parasite burdens. Reed (2014) reviews the research on parasitic species infecting commercially important marine fishes in sub-Saharan Africa and shows that very little research has been conducted into the use of parasitological data to advise fisheries management strategies in this region. Lester and Moore (2014) recapitulate those studies carried out in the largest region considered in this Special Issue, including Australasia, East Asia and the Pacific Islands. They also provide a comparative analysis of the statistical approaches used to examine parasite data in the region. MacKenzie and Hemmingsen (2014) provide a critical review on the use of parasites as biological tags in European Atlantic waters, excluding the Mediterranean and Black Seas, highlighting how parasites can be, and have been, misused as biological tags, and how this can be avoided. They also review recent developments in methodology and parasite genetics, consider the potential effects of climate change on the distributions of both hosts and parasites, and suggest host-parasite systems that should reward further research. Mattiucci et al. (2014) review the research carried out on the simultaneous use of population genetic analysis and parasites as biological tags to assess population structuring of fish species from the Mediterranean Sea. Results of metaanalyses suggested that the combination of fish genetics and parasites produced stronger information on the fish population structure than that indicated by a single dataset. Congruencies and incongruences in depicting fish stock structure from analyses of both datasets are discussed in the light of the biological features of each target species. Finally, research on biological tags in both Atlantic and Pacific waters of North America and the Caribbean is analysed by Marcogliese and Jacobson (2014), who analyse the relative differences in the ability of parasites to discriminate between fish stocks on the Pacific and Atlantic coasts, as well as their causes in relation to environmental differences between the regions. They also summarize current knowledge in North America about biological tags applied to fresh water and anadromous fishes.

In the present Special Issue, the use of parasites as biological tags is also evaluated under the perspectives of specialists in related disciplines, such as parasite taxonomists, fisheries biologists and parasite ecologists. Bray and Cribb (2014) review what is known about cryptic species in aquatic hosts and its potential importance in the effective use of biological tags in stock assessment. Van der Lingen et al. (2014) demonstrated that incorporating parasite data in fish population structure studies, under a multidisciplinary approach, has provided results that contributed to a changed understanding of the population structure of South African sardine, with significant implications for management of this fishery. Poulin and Kamiya (2014) performed a meta-analysis of the use of parasites as tags of marine fish populations in multivariate discriminant analyses, obtained from published articles; their results validate the usefulness of parasites as tags, finding that this method allows a 2 -fold improvement in the rate of correct classification compared to random classification. Finally, Wood and Lafferty (2014) analysed the relationship between parasites and fisheries under a different perspective, assessing how fisheries have affected parasite communities. Their meta-analysis contrasting parasite assemblages in fished and unfished areas suggests that parasite assemblages are likely to change substantially in composition in increasingly heavily fished ecosystems, and that parasite life history and the fishing status of the host are important in predicting the response of individual parasite species or groups to fishing.

Since the beginning of the use of parasites as biological tags, several general and regional reviews and guidelines have been published, including some recent papers (Timi, 2007; Lester and MacKenzie, 2009; Catalano et al. 2013; MacKenzie and Abaunza, 2013). However, the contributions in this Special Issue represent the largest compilation of the relevant literature, with the broadest geographical coverage so far achieved. A chronological and geographical analysis of 294 publications on the use of parasites as biological tags for marine species (excluding reviews) shows a steady increase in the number of publications 


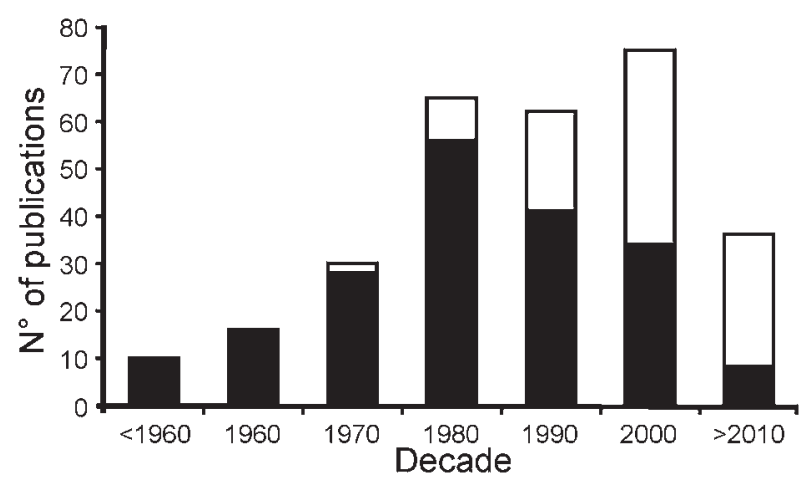

Fig. 1. Number of publications on parasite tags in marine and anadromous fishes by decade. Black: Europe and North America (Pacific and Atlantic coasts); white: rest of the world.

per decade (Fig. 1). Initially, this research was based mainly on studies in North America and Europe, but papers coming from these regions have gradually declined in number since the 1980 s, whereas in more recent times most of the relevant literature has come from the Southern Hemisphere (Southern Atlantic, Indian and Southern Pacific Oceans) and the Western North Pacific. From a regional perspective, it is also evident that most research has been carried out in temperate oceans, with fewer publications from studies conducted in tropical (mostly from Northern Australia) and polar regions.

The overwhelming majority of published papers deal with parasites of bony fishes, with very few studies on elasmobranchs and invertebrates of commercial interest (scallops, prawns, lobsters and squids). However, the number of exploited fish species evaluated under the perspective of parasite tags represents only a minor proportion of world capture fishery production. The use of parasites as biological tags will become increasingly efficient as research provides new information on parasite life cycles and basic biology. We can therefore confidently predict that this methodology will continue to contribute valuable information on stock identification and migratory behaviour in many more species of marine fishes and invertebrates.

\section{MARINE PARASITES IN MARICULTURE}

Although global capture fishery production is stagnating, global production of fish from aquaculture has grown at an impressive rate over recent decades and continues to be the fastest-growing animal food producing sector (FAO Fisheries and Aquaculture Department, 2010), currently accounting for nearly $40 \%$ of the world total fish production (FAO, 2013). At present, aquaculture is perceived as having the greatest potential to produce more fish to meet the growing demand for safe and good quality aquatic food (FAO Fisheries and Aquaculture Department, 2010).
The rapid development of mariculture has been associated with the emergence of diseases, some new and some previously known. Fish farming practices, by maintaining large numbers of fish confined in a small area, create conditions that can increase the risk of outbreaks of disease by providing increased density of fish, repeated introduction of naive hosts, homogeneous host populations, fast growth and a potential decrease in genetic diversity (Nowak, 2007).

Among pathogens commonly reported from cultured fishes, which also include viral, bacterial and fungal infections, both protozoan and metazoan parasites pose significant threats to successful aquaculture. Their prevention, control and eradication from culture systems are of paramount importance for the efficient production of maricultured fish and have prompted the development of applied fish parasitology, an increasing field that mirrors the expansion of aquaculture.

In this Special Issue, Buchmann (2014) contributes an updated review of the impact of protozoan parasites on maricultured fishes. In it he provides details on their biology and impact on productivity and evaluates tools for their diagnosis, control and management, with emphasis on antiprotozoan immune responses in fish and strategies for the development of vaccines. Similarly, Ogawa (2014) addresses the status of metazoan parasites in mariculture, reviewing those diseases caused by Platyhelminthes (Monogenea, Trematoda and Cestoda) and focusing on their biology, pathogenicity and associated host responses, as well as on control methods. The problems associated with the international trade in marine fish for aquaculture, as well as the transmission of parasites between farmed and wild fish, are also discussed. The economic impact of parasites on global finfish and shellfish aquaculture is the subject of the review by Shinn et al. (2014). These authors examine the world's major marine and brackish water aquaculture production industries and provide estimates of the potential economic costs attributable to a range of key parasite pathogens. They also describe how estimation of the economic costs of a parasite event is frequently complicated by the complex interplay of numerous factors that can be associated with a specific incident, which may extend from direct production losses to downstream socioeconomic impacts on livelihoods and satellite industries associated with the primary producer.

\section{CONCLUDING REMARKS}

Global population is expected to reach 9 billion by 2050, and the world food-producing sector must secure food and nutrition for the growing population through increased production. Production increase must occur in a context where resources necessary for food production are even scarcer in a more crowded world, and thus the sector needs to be far more 
efficient in utilizing productive resources. Fisheries and aquaculture must address many of these difficult challenges, since they have the potential to provide further and rapid increases in fish supply.

In this Special Issue, we have shown that marine parasites play many roles in fisheries and aquaculture, in some cases helping to solve problems of productivity, whereas in others presenting problems to be solved. Parasites are ubiquitous, with more parasitic than free-living species described (Windsor, 1998), and parasitic forms are to be found in all the major taxonomic groups under human exploitation. The papers in this Special Issue demonstrate the importance of parasites in both natural and artificial systems and emphasize the need for further research on their biology and particularly their relationships with their hosts.

\section{ACKNOWLEDGEMENTS}

Finally, we wish to acknowledge the efforts of all the specialists who contributed to this Special Issue. Special thanks are due to Dr Leslie Chappell for his constant support and guidance during its production.

\section{REFERENCES}

Begg, G. A. and Waldman, J. R. (1999). An holistic approach to fish stock identification. Fisheries Research 43, 35-44. doi: 10.1016/S0165-7836(99) 00065-X.

Bray, R. and Cribb, T. (2014). Are cryptic species a problem for parasitological biological tagging for stock identification of aquatic organisms? Parasitology (in press).

Buchmann, K. (2014). Impact and control of protozoan parasites in maricultured fishes. Parasitology (in press).

Cadrin, S. X., Friedland, K. D. and Waldman, J. R. (2005). Stock Identification Methods: Applications in Fishery Science. Elsevier Academic Press, Amsterdam.

Cantatore, D. M. P. and Timi, J. T. (2014). Marine parasites as biological tags in South American Atlantic waters, current status and perspectives. Parasitology (in press).

Catalano, S. R., Whittington, I. D., Donnellan, S.C. and Gillanders, B. M. (2013) Parasites as biological tags to assess host population structure: guidelines, recent genetic advances and comments on a holistic approach. International Fournal for Parasitology: Parasites and Wildlife. http://dx.doi.org/10.1016/j.ijppaw.2013.11.001

Costello, C., Ovando, D., Hilborn, R., Gaines, S. D., Deschenes, O. and Lester, S. E. (2012). Status and solutions for the world's unassessed fisheries. Science 338, 517-520. doi: 10.1126/science.1223389.

FAO (2012). The State of World Fisheries and Aquaculture 2012, FAO, Rome, 209 pp.

FAO Fisheries and Aquaculture Department (2010). World aquaculture 2010. Technical Paper No. 500/1. FAO, Rome, 105 pp.
FAO Fisheries and Aquaculture Department (2013). Global Aquaculture Production Statistics for the year 2011. ftp://ftp.fao.org/FI/ news/GlobalAquacultureProductionStatistics2011.pdf

George-Nascimento, M. and Oliva, M.E. (2014). Fish population studies using parasites from the Southeastern Pacific Ocean: considering host population changes and species body size as sources of variability of parasite communities. Parasitology (in press).

Herrington, W. C., Bearse, H. M. and Firth, F.E. (1939) Observations on 748 the life history, occurrence and distribution of the redfish parasite Sphyrion lumpi. US Bureau of Fisheries Special Report 5, 1-18.

Kleisner, K., Froese, R., Zeller, D. and Pauly, D. (2012). Using global catch data for inferences on the world's marine fisheries. Fish and Fisheries 14, 293-311. doi: 10.1111/j.1467-2979.2012.00469.

Lester, R. J. G. and MacKenzie, K. (2009). The use and abuse of parasites as stock markers for fish. Fisheries Research 97, 1-2. doi: 10.1016/j. fishres.2008.12.016.

Lester, R. J. G. and Moore, B. (2014). Parasites as valuable stock markers for fisheries in Australasia, East Asia and the Pacific Islands. Parasitology (in press).

MacKenzie, K. (1987). Parasites as indicators of host populations. International fournal for Parasitology 17, 345-352.

MacKenzie, K. and Abaunza, P. (2013). Parasites as biological tags. In Stock Identification Methods. Applications in Fisheries Science, 2nd Edn (ed. Steven, X., Cadrin, S. X., Kerr, L. A. and Mariani, S.), pp. 185-204. Elsevier Academic Press, San Diego, USA.

MacKenzie, K. and Hemmingsen, W. (2014). Parasites as biological tags in marine fisheries research: European Atlantic waters. Parasitology (in press).

Marcogliese, D. J. and Jacobson, K. C. (2014). Parasites as biological tags of marine, freshwater and anadromous fishes in North America from the tropics to the Arctic. Parasitology (in press).

Mattiucci, S., Cimmaruta, R., Cipriani, P., Abaunza, P., Bellisario, B. and Nascetti, G. (2014). Integrating parasites data and host genetic structure in the frame of an holistic approach for stock assessment in Mediterranean Sea fish species. Parasitology (in press).

Nowak, B. F. (2007). Parasitic diseases in marine cage culture - an example of experimental evolution of parasites? International Fournal of Parasitology 37, 581-588. doi: 10.1016/j.ijpara.2007.01.003.

Ogawa, K. (2014). Diseases caused by Platyhelminthes (Monogenea, Digenea, Cestoda). Parasitology (in press)

Poulin, R. and Kamiya, T. (2014). Parasites as biological tags of fish stocks: a meta-analysis of their discriminatory power. Parasitology (in press).

Reed, C. (2014). A review of parasite studies of commercially important marine fishes in sub-Saharan Africa. Parasitology (in press).

Rohde, K. (2002). Ecology and biogeography of marine parasites. Advances in Marine Biology 43, 1-83.

Shinn, A. P., Pratoomyot, J., Bron, J. E., Paladini, G., Brooker, E. E. and Brooker, A. J. (2014). Economic costs of protistan and metazoan parasites to global mariculture. Parasitology (in press).

Timi, J. T. (2007). Parasites as biological tags for stock discrimination in marine fish from South American Atlantic waters. Fournal of Helminthology 81, 107-111. doi: 10.1017/S0022149X07726561.

Van der Lingen, C., Weston, L.F., Ssempa, N. N. and Reed, C. C. (2014). Incorporating parasite data in population structure studies of South African sardine Sardinops sagax. Parasitology (in press).

Windsor, D. A. (1998). Most of the species on earth are parasites. International Fournal for Parasitology 28, 1939-1942.

Wood, C. L. and Lafferty, K. D. (2014). How have fisheries affected parasite communities? Parasitology (in press). 